\title{
Temperature extremes in the Mediterranean area: trends in the past and assessments for the future
}

\author{
E. Hertig, S. Seubert, and J. Jacobeit \\ Institute for Geography, University of Augsburg, Germany \\ Received: 13 January 2010 - Revised: 29 July 2010 - Accepted: 29 August 2010 - Published: 5 October 2010
}

\begin{abstract}
Trends of Mediterranean extreme temperatures are analysed for the period 1961-1990 based on daily station time series. Increases can be identified in the western Mediterranean area, whereas an opposite trend becomes apparent for the eastern Mediterranean region. Assessments of the 95th percentile of maximum temperatures in summer and of the 5 th percentile of minimum temperatures in winter for the 21 st century under enhanced greenhouse warming conditions are performed by means of statistical downscaling techniques. Mainly increases of both extreme indices result from these assessments, but considerable differences arise when using different predictors or predictor combinations, respectively. Furthermore, the results give strong indications that changes in temperature extremes do not follow a simple shift of the whole temperature distribution to higher values.
\end{abstract}

\section{Introduction}

Due to the high climatic variability of subtropical latitudes and the complex topography of the Mediterranean region, this area is affected by both cold temperature events (mainly during the winter months) as well as extreme hot conditions (especially during the summer season). It is well known that agriculture in the Mediterranean area is widely based on thermophile plants which only show a limited tolerance to cold temperatures. On the other hand, extreme hot days represent a serious constraint for human health, economic facilities and natural ecosystems.

Furthermore, the Mediterranean area is regarded as a "climate change hot-spot" (Giorgi, 2006) being highly affected by future climate change compared to other regions of the world. This is mostly due to the assessed decrease of pre-



Correspondence to: $\mathrm{E}$. Hertig (elke.hertig@geo.uni-augsburg.de) cipitation and water availability as well as to an increase in the inter-annual precipitation variability, but changes in temperature, especially in its extreme tails, have also to be taken into account.

Therefore, more reliable information on the evolution of the Mediterranean climate is required, particularly with respect to extreme events.

According to the latest IPCC-Report (Christensen et al., 2007) the annual warming rate from 1980-1999 to 2080 2099 , simulated with dynamical models, reached values from $2.3^{\circ} \mathrm{C}$ up to $5.3^{\circ} \mathrm{C}$ for the Southern European/Mediterranean area under A1B-scenario assumptions with the largest warming during the summer months. Statistical downscaling for B2-scenario conditions indicates the increases of mean temperature for the Mediterranean area during the period 20712100 compared to $1990-2019$ of mostly between $2^{\circ}$ and $4{ }^{\circ} \mathrm{C}$ (Hertig and Jacobeit, 2008).

Regarding the temperature extremes, global general circulation models indicate a significant downward trend during the 21 st century for the globally averaged intra-annual extreme temperature range (i.e. the difference between the highest and the lowest temperature of the year) according to greater increases in nighttime minima compared to daytime maxima. But for the Mediterranean area, an opposite trend towards an increase of the intra-annual extreme temperature range has been found (Tebaldi et al., 2006). Regarding frost days (minimum temperature below $0{ }^{\circ} \mathrm{C}$ ), a decrease is indicated along the Mediterranean and Atlantic coasts. The change of warm nights (minimum temperature above the 90th percentile) is found to be significantly positive all over the globe. Within the PRUDENCE project (prediction of regional scenarios and uncertainties for defining European climate change risks and effects; including the Mediterranean area northwards of $35^{\circ} \mathrm{N}$ ) the high-resolution dynamical models show that the inter-annual temperature variability is likely to increase in summer, whereas in winter a reduced temperature variability is identified (Kjellström et al., 2007).

Published by Copernicus Publications on behalf of the European Geosciences Union. 




Fig. 1. Location of the stations with minimum and maximum temperature data in the Mediterranean area.

Results from the STARDEX project (Statistical and regional dynamical downscaling of extremes for European regions) indicate increases in mean and extreme temperatures during all seasons in the Italian Emilia-Romagna region (Tomozeiu et al., 2007). Also Goubanova and Li (2007) find an increase in annual minimum and maximum temperatures over the Mediterranean region.

In this study, Mediterranean extreme temperatures will be analysed with regard to observed trends before an assessment, for the 21st century under enhanced greenhouse warming conditions, is performed by means of statistical downscaling techniques. The general background that meteorological extremes are related to the large-scale atmospheric circulation (see, for example, Jacobeit et al., 2009) leads to the derivation of statistical relationships between a set of large-scale atmospheric variables (predictors) and stationbased extremes indices (predictands). After a particular verification procedure, the response of future extreme temperatures in the Mediterranean area to simulated climate model changes of the large-scale predictors will be identified.

\section{Data and methods}

\subsection{Data}

Daily station data for the Mediterranean area has been collected from the GLOWA Jordan River Project (Global Change and the Hydrological Cycle, Kunstmann et al., 2006), from the EMULATE project (European and North Atlantic daily to MULtidecadal climATE variability, Moberg et al., 2006), from the European Climate Assessment \& Dataset (Klein Tank et al., 2002), and by particular MedCLIVAR cooperation. After testing homogeneity (Wijngaard et al., 2003) and applying tests on the completeness (Moberg and Jones, 2005) of the daily data, 72 stations for minimum temperature and 75 stations for maximum temperature could be retained for subsequent analyses. Locations of these stations are mapped in Fig. 1. Unfortunately almost no station is available so far over the southern Mediterranean area, especially in the countries of Northern Africa, but for the other regions rather good station coverage with daily data has been achieved. However, due to the fact that the stations are only characteristic for a limited spatial area and that skilful downscaling models cannot be established for all of these stations (see Sect. 4.2), the study does not claim to be representative for the whole Mediterranean area.

As large-scale atmospheric predictors, sea level pressure (SLP) and geopotential heights of the $500 \mathrm{hPa}$-level are taken from the NCEP/NCAR reanalysis project (Kalnay et al., 1996; Kistler et al., 2001) for the period 1950-2006. These two variables are selected to include the large-scale atmospheric circulation into the statistical downscaling models. Additionally, air temperature of the $850 \mathrm{hPa}$-level and thickness of the $1000 \mathrm{hPa}-500 \mathrm{hPa}$-layer (which represents the air temperature between the two levels) are included to represent the large-scale thermal properties of the atmosphere. To account for moisture conditions, relative humidity of the $700 \mathrm{hPa}$-level has also been considered. The spatial domain for all predictor variables ranges from $20^{\circ} \mathrm{N}$ to $70^{\circ} \mathrm{N}$ and from $40^{\circ} \mathrm{E}$ to $50^{\circ} \mathrm{W}$.

Model Output of two different coupled general circulation models (CGCMs, ECHAM5/MPI-OM, Roeckner et al., 2006a, b; Jungclaus et al., 2006; UKMO- HadCM3, Gordon et al., 2000; Pope et al., 2000) for two different emission scenarios (SRES A1B and SRES B1, Nakicenovic and Swart, 2000) has been selected, resulting in a total of 9 simulation runs (including some ensemble members) which are available for the assessment of Mediterranean temperature extremes from large-scale predictors.

In the following discussion of results, one particular run from the ECHAM5 model under SRES A1B assumptions is considered (ECHAM5 SRES A1B RUN1), because the focus of this paper is on the influence and relevance of different predictor types for assessing Mediterranean extreme temperature changes in the 21 st century. Discussing intraand inter-model differences in detail is beyond the scope of this paper. However, the variation of the statistical downscaling results arising from the use of different CGCM output is also addressed by showing the temporal progression of the 95th percentile of maximum temperatures in summer at the stations of Lisbon and Jerusalem in Fig. 8 (discussion see Sect. 4.2).

The ability of the CGCMs to reproduce the present day variability has been checked by comparing the output of the 20th century control runs to the NCEP/NCAR reanalysis data in the study period 1950-2006. For the ECHAM5 model (which is predominantly used to present results in detail) it is revealed that in summer mean geopotential heights are generally too high (too low) in the control runs compared to the reanalysis data south (north) of approximately $40^{\circ} \mathrm{N}$ $(50 \mathrm{~N})$, implying an overall stronger meridional pressure gradient in the CGCM control simulations. In winter, there are lower mean values of geopotential heights in the control runs compared to the reanalysis data mainly over the North Atlantic area between $40^{\circ} \mathrm{N}$ and $60 \mathrm{~N}$, and higher mean values over Northern Africa. Thus, in winter the low pressure systems of the extratropical frontal zone and the subtropical high pressure systems are over-emphasized in the ECHAM5 control experiments. Regarding the variances of 
the geopotential height data in the selected spatial domain $\left(20^{\circ} \mathrm{N}-70^{\circ} \mathrm{N}, 40^{\circ} \mathrm{E}-50^{\circ} \mathrm{W}\right)$, generally no significant differences between control experiments and reanalysis data are evident (Student-distributed test statistics, 99\% significance level).

In addition to the comparison of the reanalysis fields and the model data in terms of the differences of the mean values and variances, a comparison of the corresponding principal components (PCs) resulting from s-mode principal component analysis (PCA) of the NCEP/NCAR reanalysis data and of the ECHAM5 control runs for the period 1950-2006 has been done (details on PCA see Sect. 2.2). Despite the assessment of temperature extremes under future climate conditions the CGCM data projected onto the "observed" NCEP/NCAR PCs, it is of general interest whether the predictor PCs in the model data are substantially the same as in the reanalysis. Examining the ability of the ECHAM5 model to reproduce the "observed" predictors shows that the sequence and the amount of explained variance of the ECHAM5 PCs is somewhat different compared to the PCs of the NCEP/NCAR reanalysis (with a maximum difference in the amount of explained variance of about $8 \%$ for a specific PC). Additionally, the centres of variation (areas of high PC loadings) display some spatial shifts and/or minor differences in intensity. Notwithstanding, there is a distinct consistency of the overall structure of the ECHAM5 control run PCs and the reanalysis PCs, in particular those PCs with lesser amounts of explained variance.

Despite some deficiencies in the ECHAM5 model capturing all aspects of natural variability correctly, the pressurerelated variables are regarded as useful predictors to assess regional climate change. However, in the discussion of results (Sect. 4) the shortcomings of the CGCMs have to be kept in mind.

\subsection{Statistical methods}

To represent extreme temperature conditions, the 5th percentile of daily minimum temperatures and the 95th percentile of daily maximum temperatures are calculated for all available station data in the period 1950-2006. The percentiles are calculated for overlapping two-month periods (January/February, February/March, ...) as well as for the traditional seasons (March to May, June to August, September to November, and December to February). The percentiles are computed for each individual season without the use of a particular reference percentile from a predefined base period. The advantage of variable percentiles may be seen in the possibility to use interval-scaled data with a consistent temporal resolution in contrast to the indices resulting from counting the number of events falling below or exceeding a specific reference percentile in a particular season.

Trends in Sect. 3, and most of the assessment results in Sect. 4, are presented for the 5th percentile of minimum temperatures in winter and for the 95th percentile of max- imum temperatures in summer. Concerning minimum temperatures in winter, the question whether the frost hazard risk has changed or will change concomitantly with global warming. Concerning maximum temperatures in summer, as an indicator of possible heat stress conditions, the question will be addressed whether the hottest days have already become hotter in the recent past or will get even hotter in the future by enhanced greenhouse warming.

Linear trends of the extreme indices are calculated for the period 1961-1990 to identify their behaviour in the recent past and to define a reference for the estimated future changes. The reference period for trend calculations comprises only 30 years, because it is the only time interval with complete temperature data for all stations. The trends are calculated as linear regressions, and their significance is tested by the non-parametric Mann-Kendall test (Mann, 1945) with a significance level of 0.1 .

Principal component analysis (PCA, e.g. Preisendorfer, 1988; von Storch and Zwiers, 1999) is applied to the different predictor fields and to the predictor combinations in order to remove linear dependencies between variables and to reduce dimensions of the data. In the present study, Smode (Richman, 1986), orthogonally (Varimax-criterion) rotated PCAs are carried out for the whole study period from 1950 to 2006 and also for five different calibration periods (see at the end of this section), resulting in spatial centres of variation and associated time coefficients for each calibration period. The determination of the number of PCs to be extracted follows the approach of Philipp et al. (2007) and is based on the criterion that each PC has to be uniquely representative for at least one input variable. Representativeness is assumed when the maximum loading of a variable on a particular PC is at least one standard deviation greater than the other loadings of this variable on the remaining PCs; additionally, this maximum loading has to be statistically significant at the $95 \%$ level. Depending on the particular season, SLP and $500 \mathrm{hPa}$-geopotential height fields are reduced to 6 (SLP, January/February) up to $13 \mathrm{PCs}(500 \mathrm{hPa}-$ geopotential heights, June/July) with overall explained variances (EVs) between $88 \%$ and $96 \%$. $850 \mathrm{hPa}$ air temperature and $500 \mathrm{hPa}-1000 \mathrm{hPa}$-thickness fields are condensed to 9 (January/February) up to 18 PCs (June/July) with EVs of $88 \%$ to $93 \%$. $700 \mathrm{hPa}$ relative humidity fields are reduced to 14 (September/October) up to 20 PCs (mainly spring and summer months) with EVs between $70 \%$ and $90 \%$.

Subsequently, using the data for the whole study period 1950-2006, stepwise multiple regressions (e.g. von Storch and Zwiers, 1999, p. 166) with 1000 iterations of bootstrapping have been performed for each extreme temperature time series as predictand and a specific predictor or predictor combination, respectively. The F-test is used for entering and maintaining variables in the regression equations. Further diagnostic procedures are applied to examine the residuals, the multiple correlation coefficients and the partial regression coefficients. The regression analysis of the whole study 


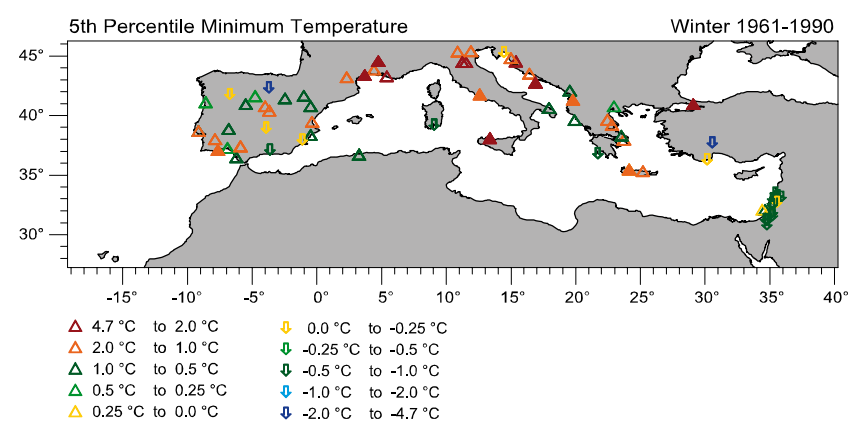

Fig. 2. Trends of the 5th percentile of minimum temperature in winter (December to February) for the period 1961-1990. Colourfilled symbols indicate significant trends at the $90 \%$ level.

period is used for an improved selection of predictors based on frequency statistics of the predictors being selected during the 1000 iterations mentioned above. Those independent variables which are most frequently selected in the stepwise regression model ensemble are taken as predictors for further analyses. This means that multiple regression analyses are now performed with fixed predictor sets and without a stepwise selection among the independent variables. These final analyses are realised for five different calibration periods including in each case the above-mentioned statistical quality diagnostics. Those models which meet the requirements are further tested for their performance in the corresponding verification periods.

Each of the five verification periods comprises of 10 years which are not included in the corresponding calibration periods: 1961-1970, 1971-1980, 1981-1990 and for every temperature station the first ten years and the last ten years of the extreme time series within the overall time frame of 1950-2006. The selection of three fixed verification periods ensures a good intercomparison of all stations, whereas the two variable verification periods, taking into account the differing lengths of the station time series, in particular allow the focusing on the detection of non-stationarities in the circulation-extreme events relationships.

Model performance in the verification periods is evaluated by means of the correlation coefficients between modelled and observed extremes indices. Additionally the RV-value (reduction of variance) is calculated, being similar to the root mean squared skill score. The "reference" in the present study is the mean of the observations from the verification sample. $\mathrm{RV}=100 \%$ would mean a perfect model, $\mathrm{RV}=0 \%$ implies no improvement compared to the simple use of the sample climatology, and RV $>0 \%$ indicates some improvement by the model results. In the present study, all regression models with $\mathrm{RV}>0$ pass the verification procedure and constitute a statistical model ensemble which is subsequently used for the assessment of temperature extremes under future climate conditions.

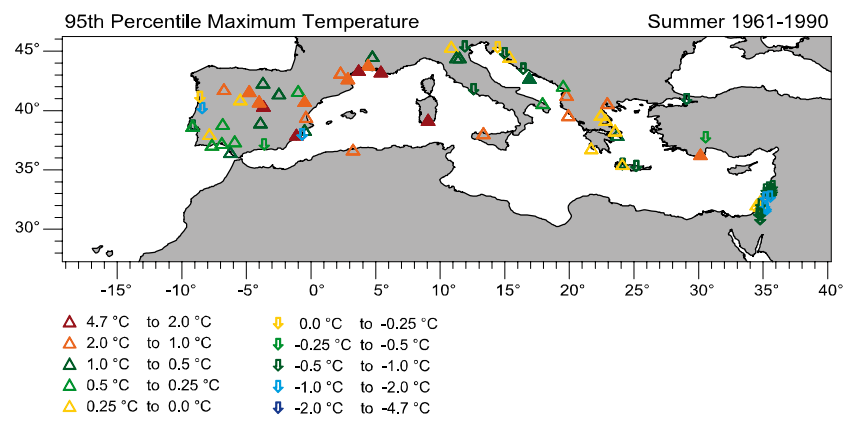

Fig. 3. Trends of the 95th percentile of maximum temperature in summer (June to August) for the period 1961-1990. Colour-filled symbols indicate significant trends at the $90 \%$ level.

\section{Trends for the period 1961-1990}

Trends for the 5th percentile of minimum temperatures in winter are presented in Fig. 2. Obviously the trends are mostly not significant during the period 1961-1990. Significant increases of the 5th percentile of minimum temperatures (marked with filled triangles) occurred mainly at stations in the central-northern Mediterranean area with values of more than $2{ }^{\circ} \mathrm{C}$ in some cases (e.g. Palermo, Italy or Istanbul, Turkey). In general, the trend pattern shows an opposite behaviour between the western and northern Mediterranean region (predominantly increases of the extremes index) and the eastern Mediterranean area (mostly decreases).

Figure 3 shows the trends for the 95th percentile of maximum temperatures in summer 1961-1990. Again, an opposite trend pattern can be seen with mostly increases in the western Mediterranean area and decreases in the eastern Mediterranean region. The largest increases can be found over the Iberian Peninsula and southern France with values between $1^{\circ} \mathrm{C}$ and $2{ }^{\circ} \mathrm{C}$ (filled orange triangles) or even above $2^{\circ} \mathrm{C}$ (filled red triangles) at some stations. In the central-northern Mediterranean area non-significant trends (decreases as well as increases) predominate.

Mean temperatures in winter also show a slight cooling trend in the eastern Mediterranean area and a significant warming in the western Mediterranean region during the second half of the 20th century (Jacobeit, 2008). Thus, mean temperatures as well as extreme minimum and maximum temperatures exhibit an opposite behaviour between the eastern and the western Mediterranean area, pointing to the concept of the "Mediterranean Oscillation", a pressure seesaw between the western-central and the eastern Mediterranean region (e.g. Dünkeloh and Jacobeit, 2003). Due to this influence, the Mediterranean area has experienced slight cooling in some parts concomitant with the general global temperature increase in the second half of the 20th century. Thus, the effects of radiative forcing of mean and extreme temperatures can be substantially modified by circulation dynamics. 


\section{Statistical downscaling results}

\subsection{Performance of different predictors for the assessment of extreme temperatures}

The quality of different predictors and predictor combinations is evaluated in terms of their performance within the verification procedure (for details of the method see Sect. 2.2). At first the overall model performance is quite unsatisfactory. With respect to all cases being considered (approx. 5600 for a specific extreme index-predictor relationship including approx. 70 stations, 5 calibration periods and 16 seasonal sections), only for $8-12 \%$ of them a robust regression model can be established. Looking at the regression models in detail reveals some reasons for this:

- Sometimes a certain predictor performs well in a particular season, whereas it fails to reproduce extreme temperature variability in other seasons (intra-annual variability of predictability). Thus, a seasonal analysis of the predictor performance is given in the next paragraph.

- A certain predictor can also exhibit a stable connection to a particular extremes index only in some subintervals of the study period, resulting in a varying performance in the different verification periods (intra- to inter-decadal variability of predictability). These nonstationarities in the circulation-climate relationships are a widespread phenomenon in dynamical studies of climate variability lowering predictability on all time scales from seasonal to inter-decadal. In the present study non-stationarities in the circulation-extreme temperature relationships are taken into account by generating statistical model ensembles to predict future changes. Unfortunately, the training data is not long enough (maximum of 57 years) to sample all modes of variability.

- Overall model performance for a certain predictor can also depend on the location of a particular station. A spatial analysis reveals that extreme temperature conditions at different stations in the Mediterranean area depend on the differing large-scale atmospheric conditions (spatial variability of predictability). This is taken into account by fitting regression models separately for each station.

Regarding predictor performance for the 95th percentile of local maximum temperatures, the best large-scale predictor is the thickness of the $1000 \mathrm{hPa} / 500 \mathrm{hPa}$ layer. Looking at the results in detail, this atmospheric temperature indicator works best in late winter (February/March) and in the summer months. During spring, circulation-type predictors (SLP, $500 \mathrm{hPa}$-geopotential heights) are predominantly selected in the regression models, and in autumn/early winter (September to January) circulation and large-scale temperature predictors work best.

For the 5th percentile of local minimum temperatures the best overall large-scale predictors are the geopotential heights of the $500 \mathrm{hPa}-$ level. A seasonal inspection of the results indicates that the best predictors in winter are related to the atmospheric circulation (SLP, $500 \mathrm{hPa}$ geopotential heights) and those in spring to thermal conditions (1000/500 hPa thickness and $850 \mathrm{hPa}$-temperature). From April to June circulation predictors dominate again. In the summer months of July/August relative humidity of the $700 \mathrm{hPa}-$ level is often selected as an additional predictor in the regression models, and in autumn (September/October) a combination of circulation and thermal predictors works best for reproducing the local variability of the 5th percentile of minimum temperatures.

In general, the selection of large-scale predictors in this study is similar to that of Tomozeiu et al. (2007) for the Emilia-Romagna Region. They mainly identify temperatures of the $850 \mathrm{hPa}$-level as the best large-scale predictor for the 10th percentile of minimum temperatures and the 90th percentile of maximum temperatures. Further results mentioned above for the present study additionally reflect conditions from larger parts of the entire Mediterranean region.

\subsection{Statistical assessments of extreme temperatures for the 21 st century}

The focus of this section is on the variation of results arising from the use of different predictors.

The changes of the 95th percentile of maximum temperatures in summer in the period 2070-2099 are shown with respect to the period 1961-1990, resulting from statistical downscaling of ECHAM5/MPI-OM model output under SRES A1B scenario assumptions. In addition, the significance of the resulting changes is evaluated by the "signal-tonoise-ratio" (see, for example, Rapp and Schönwiese, 1995). The signal-to-noise-ratio is obtained by setting the mean difference of the two 30-year periods in relation to natural variability, represented by the standard deviation of the interannual variations within the earlier period. Stations with a signal to noise ratio being greater than 1 (see Fig. 4) do not really indicate significance (with a low confidence level of only $68 \%$ ), but they reach an amount of change being greater than the common level of variability during the reference period. Additionally, the two time intervals are tested for significant differences (95\% level) using the non-parametric U-test (Mann and Whitney, 1947).

Figure $4 \mathrm{a}$ shows the downscaling results with $1000 \mathrm{hPa} / 500 \mathrm{hPa}$ thickness as predictor variable. This predictor has the best performance for the 95th percentile of maximum temperatures in summer compared to other predictors, with a total of 90 verified statistical models for 42 temperature stations. Increases of the 95th percentile 


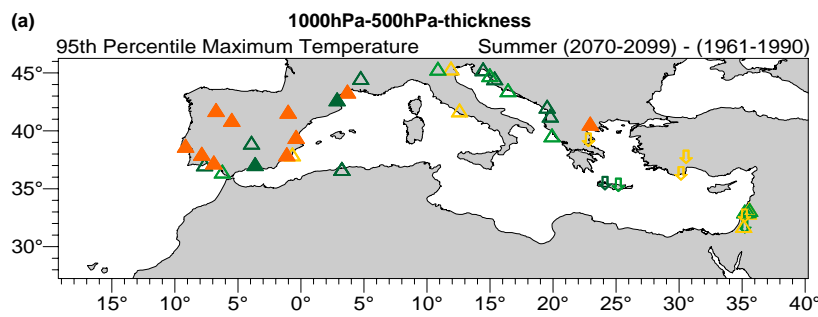

(b) 500hPa-geopotential heights

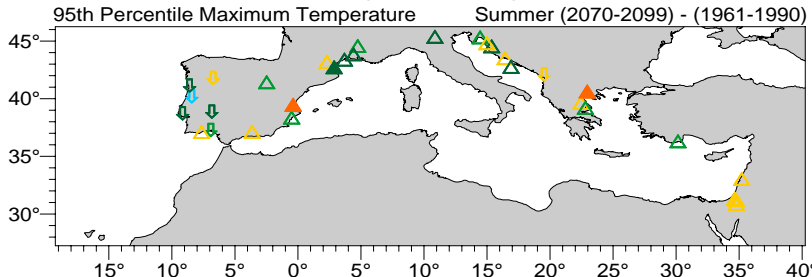

(c) $\quad 1000 \mathrm{hPa}-500 \mathrm{hPa}$-thickness $+500 \mathrm{hPa}$-geopotential heights

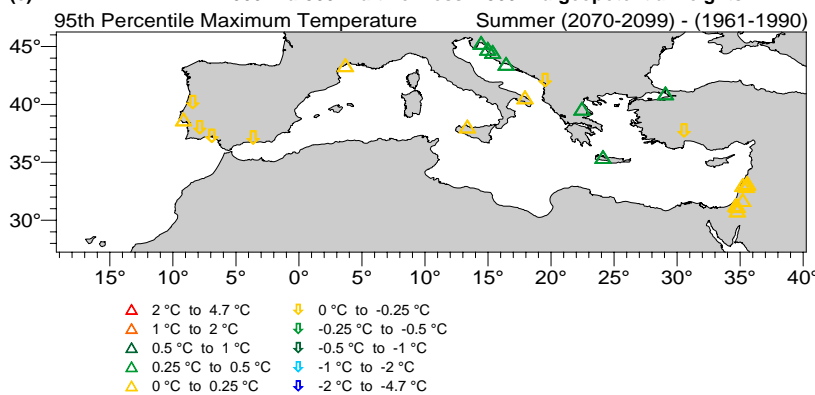

Fig. 4. Changes of the 95th percentile of maximum temperature in summer (June to August) according to statistical downscaling assessments using ECHAM5/MPI-OM predictors under SRESA1B scenario assumptions. Differences of the seasonal extreme indices between the periods $2070-2099$ and 1961-1990 in ${ }^{\circ} \mathrm{C}$. Statistical downscaling technique: Multiple Regression analysis. Colour-filled symbols: signal/noise ratio greater than 1 . (a) Predictor: $1000 \mathrm{hPa}-$ 500 hPa-thickness. (b) Predictor: $500 \mathrm{hPa}$-geopotential heights. (c) Predictors: $1000 \mathrm{hPa}-500 \mathrm{hPa}$-thickness and $500 \mathrm{hPa}$-geopotential heights.

of maximum temperatures in summer under enhanced greenhouse warming conditions are found for almost every station in the Mediterranean area. The increases are largest mainly for stations on the Iberian Peninsula with significant values up to $2{ }^{\circ} \mathrm{C}$. At some stations, for example on the Island of Cyprus, weak decreases (not significant) can be found. A comparison of the evolution of the time series of the 95th percentile of maximum temperatures in the course of the 21 st century between the western and the eastern Mediterranean area by means of selected stations (Lisbon, Portugal and Jerusalem, Israel) is illustrated in Fig. 5a. Additionally for the time series of those statistical ensemble members for which a robust regression model exists, the linear trends of the time series are included. According to the left side of Fig. 5a, the station of Lisbon depicts strong increases of the extreme maximum temperatures in summer from values of about $32{ }^{\circ} \mathrm{C}$ at the beginning of the $21 \mathrm{st}$ century to more than $35^{\circ} \mathrm{C}$ one hundred years later. In contrast to that, very weak decreases become evident for the station of Jerusalem (right side of Fig. 5a) when using the $1000 \mathrm{hPa} / 500 \mathrm{hPa}$ - thickness as predictor.

Figure $4 \mathrm{~b}$ shows the results for the same percentile and the same model output like in Fig. 4a (ECHAM5/MPIOM, SRES A1B), but now for the predictor of $500 \mathrm{hPa}-$ geopotential heights. In this case, 65 verified regression models for 31 temperature stations exist. Once again, increases of the extreme index are identified for almost all stations in the Mediterranean area, but the magnitude of these increases is somewhat different compared to the former assessment. But most notably, for the western parts of the Iberian Peninsula decreases of the extreme maximum temperatures in summer are assessed when using $500 \mathrm{hPa}$ geopotential heights as predictor. Looking at the evolution of the time series for the station of Lisbon (left side of Fig. 5b) and the station of Sed'e (right side of Fig. 5b, replacing Jerusalem for which no robust regression model exists in this case) reveals relatively strong decreases of about $2{ }^{\circ} \mathrm{C}$ of the 95th percentile for Lisbon, but a weak upward trend for Sed'e.

In view of these results, we have to conclude that the downscaling assessment of extreme maximum temperatures in summer is highly sensitive to the choice of predictors in the western parts of the Mediterranean area, whereas no such dependence is evident for stations in the eastern Mediterranean.

Concerning the results for Lisbon, the question arises about the underlying physical relationships leading to such a big difference in the downscaling results. Therefore, the different statistical models for the station of Lisbon are analysed in more detail. When using $1000 \mathrm{hPa} / 500 \mathrm{hPa}$ thickness as a predictor, the second PC of the months from June to August dominates as independent variable in the regression models. They have a multiple correlation coefficient of 0.54 (averaged over the different calibration periods), the correlation coefficients between modelled and observed extreme temperature indices are 0.64 and 0.51 in the calibration and verification periods, respectively. The RV-value amounts to 17.5\%. The upper part of Fig. 6 shows the S-mode loadings (spatial pattern) of this dominating PC. Its centre of variation is located just over Lisbon and the adjacent south-western areas. The regression coefficient is negative for this PC, which means that the positive mode (reduced thickness and, therefore, lower temperatures in the $1000 \mathrm{hPa} / 500 \mathrm{hPa}$ layer) is connected with low values of the 95th percentile at Lisbon and vice versa. Additionally, the time coefficient of this PC in the 21 st century (based on the above-mentioned model run) is reproduced on the left side of Fig. 7. It has high values at the beginning of the 21 st century, going to negative values in the second half of the 21 st century. This means that there is a change in predominance from the positive to the negative mode. Since the latter is connected to high values of the 95th percentile at Lisbon, the upward trend in Fig. 5a (left 

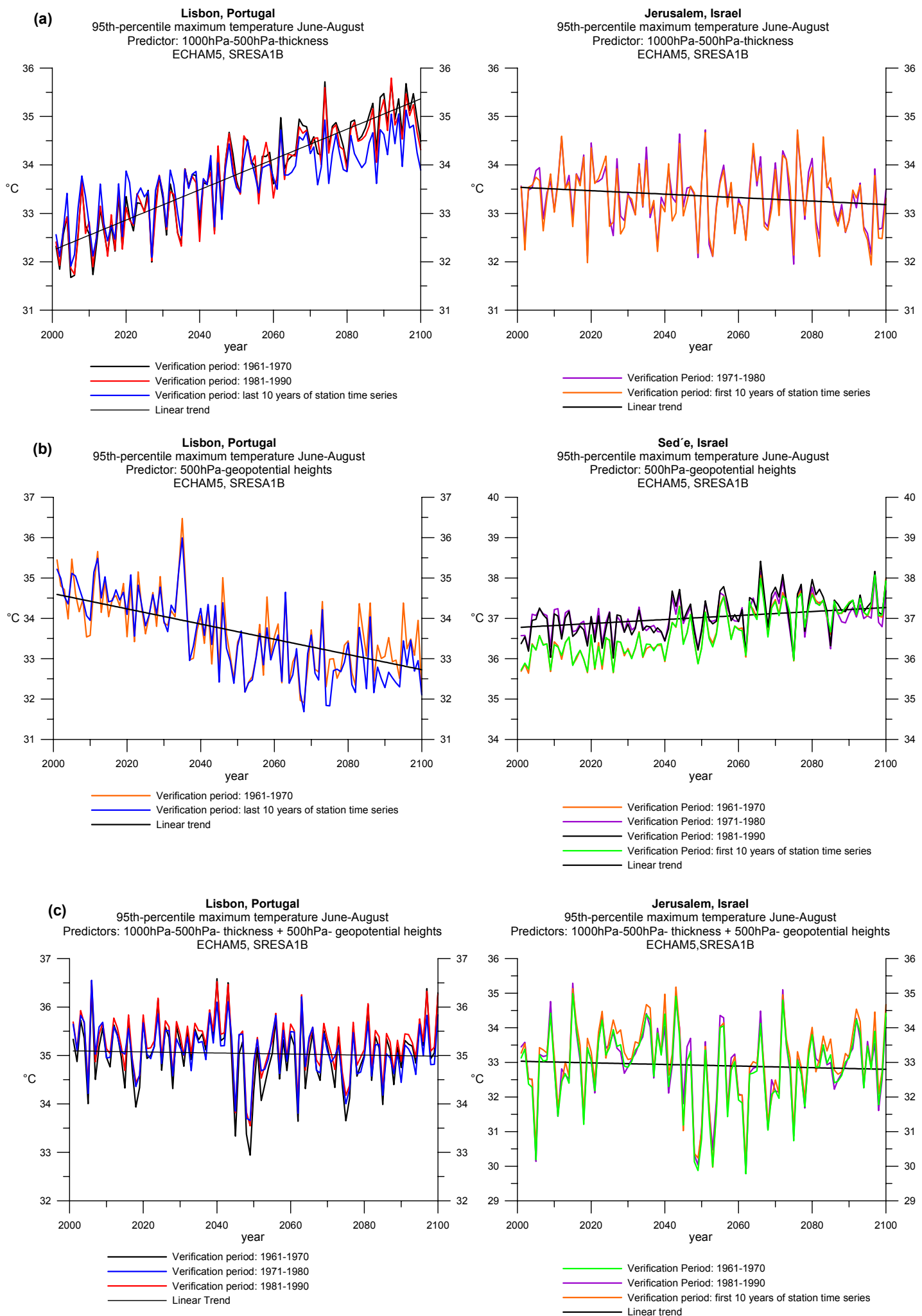

Fig. 5. Time series and linear trends of multi-member statistical downscaling ensembles of extreme (95th percentile) maximum temperature in summer 2000-2100 for three different predictors/predictor combinations ((a) $1000 \mathrm{hPa}-500 \mathrm{hPa}$-thickness, (b) $500 \mathrm{hPa}$-geopotential heights, (c) $1000 \mathrm{hPa}-500 \mathrm{hPa}$-thickness and $500 \mathrm{hPa}$-geopotential heights) for the station of Lisbon, Portugal (left side) and the station of Jerusalem (for (b): Sed'e), Israel (right side). Predictor values are from the ECHAM5/MPI-OM model run under SRESA1B scenario assumptions. The statistical downscaling technique is multiple regression analysis. 

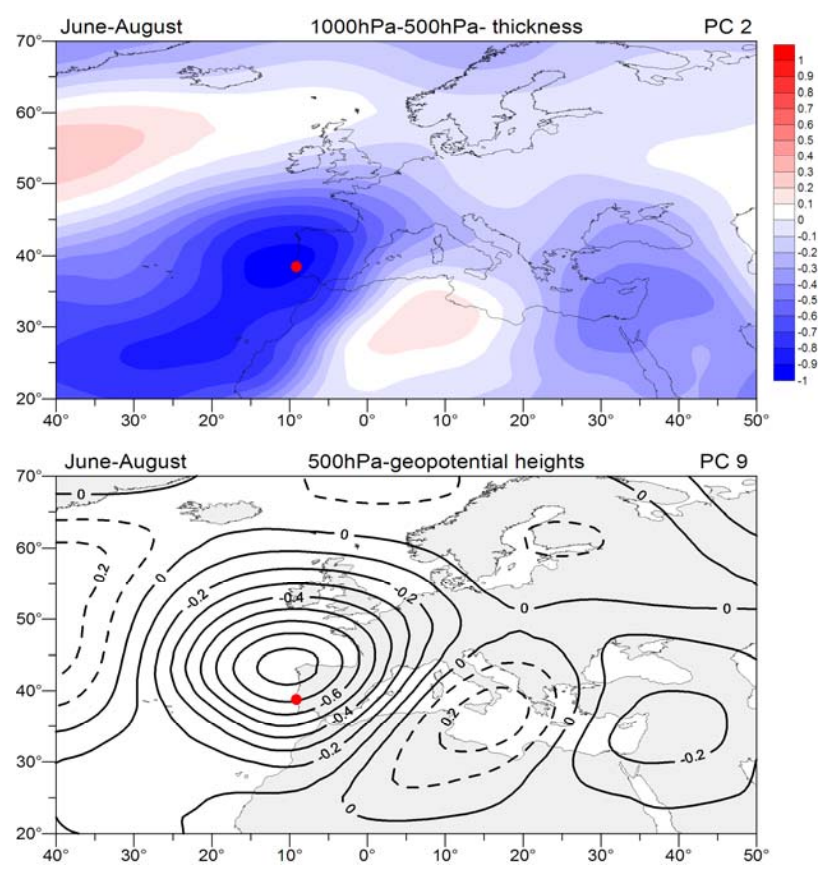

Fig. 6. Loadings of PCs which are selected as dominant independent variables in the multiple regression models for extreme maximum temperatures at Lisbon in summer (Location of the station marked by red dot). Upper figure: PC2 from the PCA of $1000 \mathrm{hPa}-$ $500 \mathrm{hPa}$-thickness in June to August 1950-2003. Lower figure: PC9 from the PCA of $500 \mathrm{hPa}$-geopotential heights in June to August 1950-2003.

side) is the corresponding result. But it has to be considered that the ECHAM5 control runs include an over-estimation of the $500 \mathrm{hPa}$-geopotential heights just in the region where the second PC of the $1000 \mathrm{hPa} / 500 \mathrm{hPa}$ thickness is located. This leads to air temperatures being too high at the centre of the variation of PC2. Consequently, the CGCM bias has a contributing effect to the statistically derived upward trend of extreme maximum temperatures at Lisbon in summer by artificially enhancing the estimated trend.

In the regression models with $500 \mathrm{hPa}$-geopotential heights as predictor, a particular PC is selected as the most important independent variable which has its centre of variation over the north-eastern part of the Iberian Peninsula and the adjacent North Atlantic Ocean (lower part of Fig. 6). Again, the regression coefficient is negative for this PC. The multiple correlation coefficient of the regression models is 0.68 (averaged over the different calibration periods), the correlation coefficients between modelled and observed extreme temperature indices amount to 0.68 and 0.5 in the calibration and verification periods, respectively. The RV-value is $10.4 \%$. Composites for the positive mode of this dominating PC (related to low values of the 95th percentile at Lisbon) and for the negative mode (combined with high values of the extreme temperature index) indicate that in the former case a high-pressure system exists over the North Atlantic Ocean with its centre above the Azores Islands, whereas in the opposite mode another high-pressure system over the North Atlantic Ocean extends further east over Europe and the central Mediterranean. Strong anticyclonic conditions over the target location favour the occurrence of extreme summer maximum temperatures at Lisbon. The time coefficient of the dominating PC (based on the ECHAM5 model run) shows a strong upward trend during the 21 st century (Fig. 7 right side) indicating a change in predominance from the negative to the positive mode. The latter is connected to lower values of extreme temperatures at Lisbon resulting in the negative trend of Fig. 5b (left side).

This is in contrast to the upward trend of extreme maximum temperatures in summer assessed by using a large-scale thermal predictor. The latter result is in accordance with the general idea that changes in temperature extremes are mainly due to the shift of the whole distribution to higher values. But this study has also determined a downward trend when using a circulation predictor. Thus, different parts of projected changes are linked to different types of predictors (climatic and dynamic ones in this case). Furthermore, Van den Besselaar et al. (2009) show that specific circulation types can exhibit even an opposite trend of temperature extremes at different European stations. In general, circulation-type predictors are regarded as skillful variables in the scope of statistical downscaling studies, because climate variables are related to the large-scale circulation and the latter is generally well-represented in global circulation models from which predictor output is used in the downscaling studies. All this leads to the conclusion that one type of predictor is not enough to assess changes in extremes under future climate conditions in an appropriate way, instead a well-defined combination of different predictor types has to be taken into account.

This has been done in the present context by using a predictor combination of both $1000 \mathrm{hPa} / 500 \mathrm{hPa}$-thickness and $500 \mathrm{hPa}$-geopotential heights. The result of this assessment with 37 verified models for 26 stations indicates only weak changes with maximum values of up to $0.5^{\circ} \mathrm{C}$ (see Fig. 4c). The time series of the statistical ensemble members for the stations of Lisbon and Jerusalem in Fig. 5c do not have a discernible trend of the 95th percentile of maximum temperatures in summer during the 21 st century. Thus, the combined effects of climatic and dynamic predictors lead to only minor changes of extreme summer temperatures in the Mediterranean region. In contrast to this, the projected changes of mean temperatures in the Mediterranean area range between $2^{\circ} \mathrm{C}$ up to about $5^{\circ} \mathrm{C}$ with an emphasis on the summer months (Christensen et al., 2007). Thus, the results of the present study indicate that some changes in the tails of the temperature distribution may not occur proportionally to changes in the mean. In this case, increases of the mean values might exceed the raise of extreme maximum values in summer. 


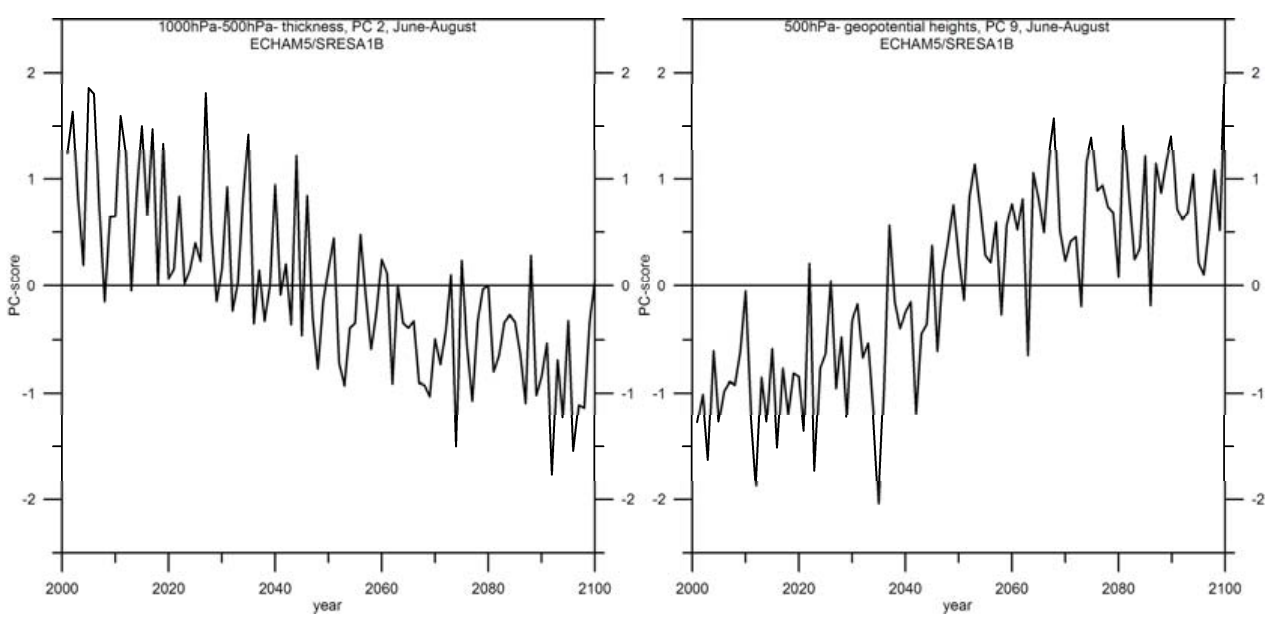

Fig. 7. Temporal evolution of PCs for the period 2000 to 2100 in the ECHAM5/MPI-OM model run under SRESA1B assumptions. Left figure: Time series (PC-scores) of the PC2 from the PCA of $1000 \mathrm{hPa}-500 \mathrm{hPa}$-thickness June-August. The corresponding PC-loadings are illustrated in the upper part of Fig. 6. Right figure: Time series (PC-scores) of the PC9 from the PCA of $500 \mathrm{hPa}$-geopotential heights June-August. The corresponding PC-loadings are shown in the lower part of Fig. 6.
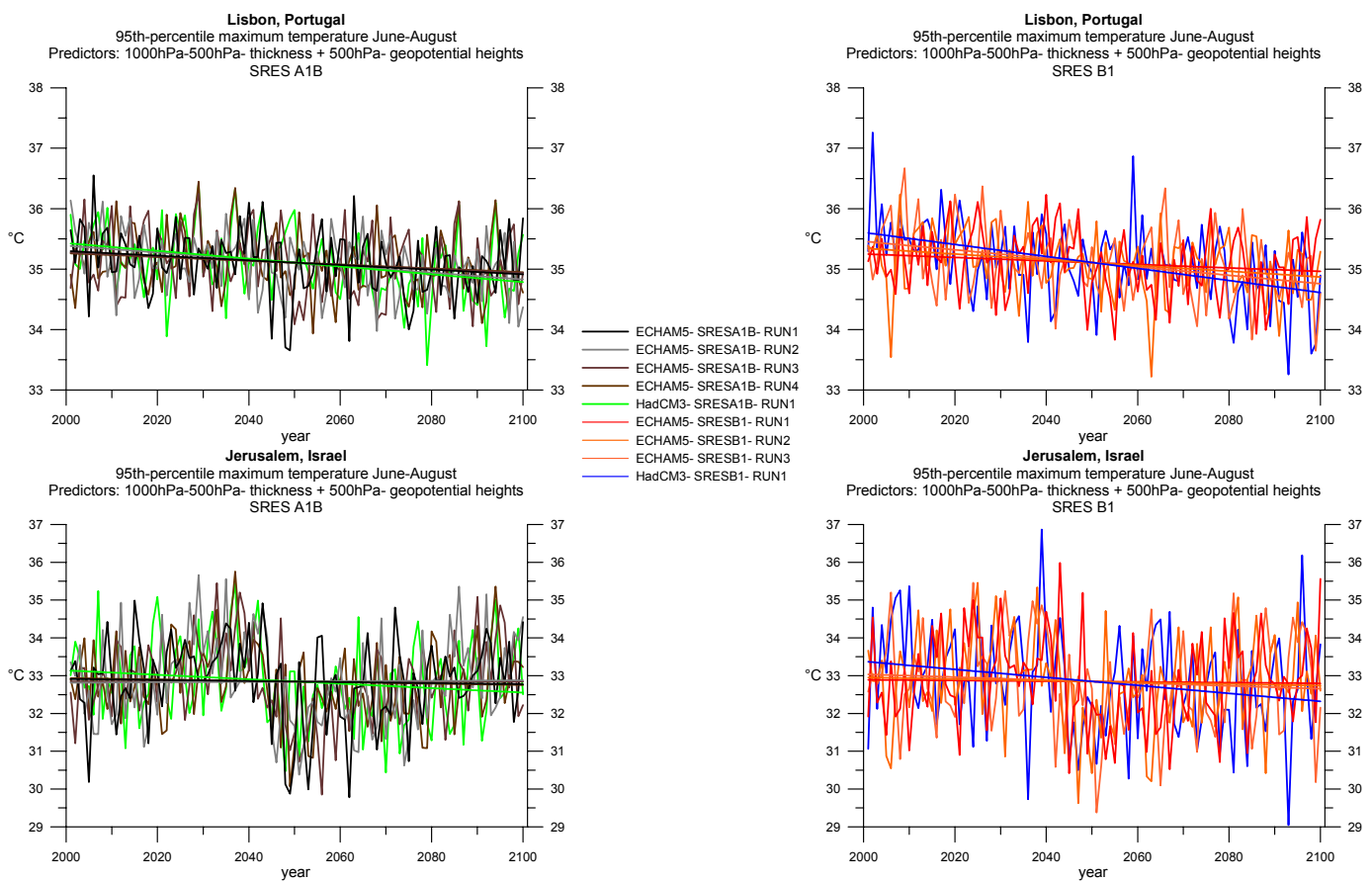

Fig. 8. Time series and linear trends of extreme (95th percentile) maximum temperatures in summer 2000-2100 from statistical downscaling of output from nine different CGCM runs for the station of Lisbon, Portugal (upper figures) and the station of Jerusalem, Israel (lower figures). Predictor values are from four ECHAM5/MPI-OM model runs and one HadCM3 run under SRES A1B scenario assumptions (left figures), from three ECHAM5/MPI-OM runs and one HadCM3 run under SRES B1 assumptions (right figures). Predictors: 1000 hPa$500 \mathrm{hPa}$-thickness and $500 \mathrm{hPa}$-geopotential heights. Statistical downscaling technique: multiple regression analysis. The assessments are based on that statistical model with the highest RV-value.

To check the consistency of the results for varying predictor sets of the same kind, but from different CGCM output, the downscaling assessments have been repeated with model output from further ECHAM5-A1B runs (3 ensemble mem- bers with slightly modified initial conditions), from different scenario assumptions (B1 instead of A1B), and also from another CGCM (HadCM3 instead of ECHAM5). Some results can be seen in Fig. 8, again for the stations of Lisbon (upper 
a: $\quad$ 500hPa-geopotential heights

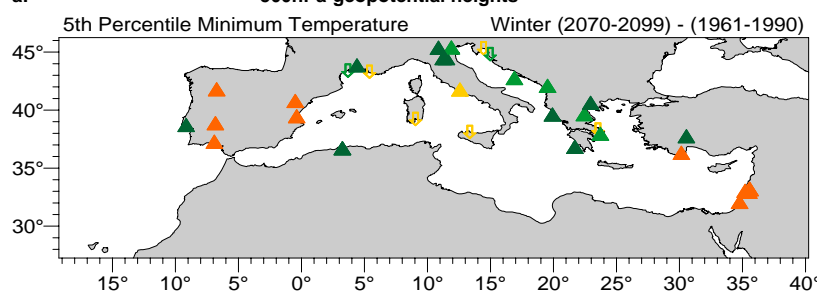

1000hPa-500hPa-thickness
b: 5 th Percentile Minimum Temperature $\quad$ Winter (2070-2099) - (1961-1990)

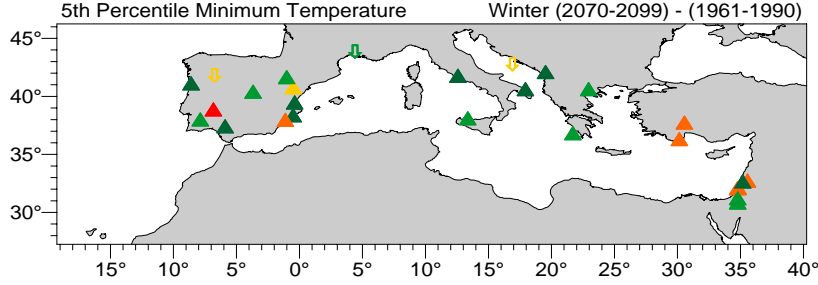

c: $\quad 1000 \mathrm{hPa}-500 \mathrm{hPa}$-thickness $+500 \mathrm{hPa}$-geopotential heights

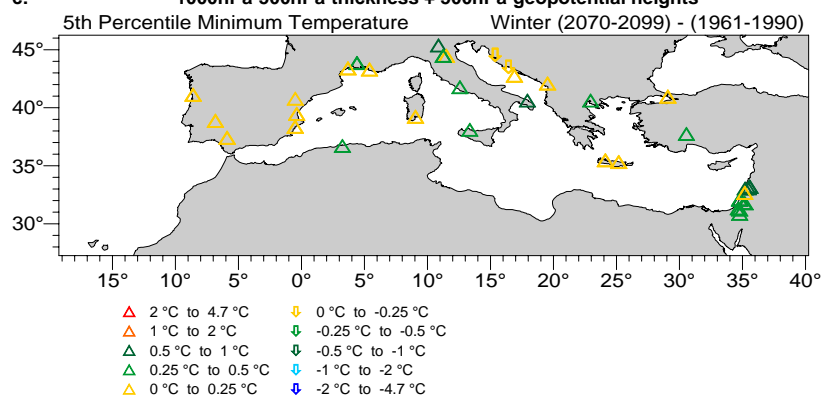

Fig. 9. Changes of the 5th percentile of minimum temperatures in winter (December to February) according to statistical downscaling assessments using ECHAM5/MPI-OM predictors under SRES A1B scenario assumptions. Differences of the seasonal extreme indices between the periods 2070-2099 and 1961-1990 in ${ }^{\circ}$ C. Statistical downscaling technique: Multiple Regression analysis. Colour-filled symbols: signal/noise ratio greater than 1. (a) Predictor: 500 hPa-geopotential heights, (b) Predictor: $1000 \mathrm{hPa}-$ $500 \mathrm{hPa}$-thickness. (c) Predictors: $1000 \mathrm{hPa}-500 \mathrm{hPa}$-thickness and $500 \mathrm{hPa}$-geopotential heights.

figure) and Jerusalem (lower figure). Obviously the assessed time series resulting from the use of different CGCM output show a good agreement among each other. The total range of variation and the trend progression are in general agreement, despite the use of different ensemble members, scenarios and CGCMs. Only the HadCM3-B1 run (blue line) shows a slight deviation regarding the overall trend, with a more pronounced downward trend of the 95th percentile of maximum temperatures in summer. Additionally it can be inferred from the range of variation of the different time series that the interannual extreme maximum temperature variability is much greater for the station of Jerusalem in the eastern Mediterranean area compared to the station of Lisbon in the western Mediterranean area.
Concerning the 5 th percentile of minimum temperatures in winter, results are shown in Fig. 9. For this index of extremes the overall best predictor are the $500 \mathrm{hPa}$-geopotential heights providing 65 skillful models for 36 stations. The future assessments show increases of about $1{ }^{\circ} \mathrm{C}$ to $2{ }^{\circ} \mathrm{C}$ in the 5th percentile index for the period 2070-2099 compared to 1961-1990 at many stations in the western as well as in the eastern Mediterranean area (Fig. 9a). In the central-northern Mediterranean area the increases are generally weaker, mainly with values of $0.25^{\circ} \mathrm{C}$ to $1^{\circ} \mathrm{C}$. At most of the stations the increases are at least greater than one standard deviation during the reference period (see filled symbols in Fig. 9a).

Figure $9 \mathrm{~b}$ indicates that $1000 \mathrm{hPa} / 500 \mathrm{hPa}$-thickness as predictor leads also mainly to increases of the extremes index (based on 50 skillful models for 27 stations). Largest values of increase reach up to about $2{ }^{\circ} \mathrm{C}$, concentrated in the eastern Mediterranean area, but the amount at individual stations is somewhat different compared to the assessment with geopotential height predictors.

Finally, Fig. 9c illustrates the changes of extreme minimum temperatures in winter resulting from the use of the predictor combination $1000 \mathrm{hPa} / 500 \mathrm{hPa}$-thickness and $500 \mathrm{hPa}$ geopotential heights. Also in this assessment an increase of extreme minimum temperatures is revealed, however, the absolute values are somewhat lower compared to the assessments with only one predictor type.

Generally there is a relatively good consistency of the statistical assessments using different predictors/predictor combinations. All versions indicate that the extreme winter minimum temperatures in the Mediterranean area will increase until the end of the 21st century. Altogether the largest increases of the 5 th percentile of minimum temperatures in winter are found for the eastern Mediterranean area.

\section{Conclusions}

Trends for extreme minimum temperatures in winter and extreme maximum temperatures in summer have been calculated for the period 1961-1990. The results revealed that the eastern parts of the Mediterranean area were affected by cooling trends despite the overall tendency of global warming. This indicates that direct effects of radiative forcing can be substantially modified by other factors, in particular, the atmospheric circulation.

Multiple regression models have been established for the whole study period 1950-2006 and for five different calibration periods with respect to the 5 th percentile of minimum temperatures in winter, the 95th percentile of maximum temperatures in summer (local predictands) and different sets of large-scale predictors. Overall model performance shows dependence on the choice of predictors, on the particular calibration/verification periods used and on the spatial location of the individual stations. For the 95th percentile of maximum temperatures in summer the best-performing 
predictor is the thickness of the $1000 \mathrm{hPa} / 500 \mathrm{hPa}-1$ layer, concerning the 5 th percentile of minimum temperatures in winter this is true for the $500 \mathrm{hPa}$-geopotential heights.

Summarizing the results of the statistical downscaling studies with respect to these extreme temperature indices leads to the following conclusions:

- Statistical downscaling of temperature extremes at stations in the Mediterranean area is hampered by widespread non-stationarities in the predictor-extreme temperature-relationships. These non-stationarities are discernible for all types of predictors. Due to the varying connections of local extremes to large-scale predictors, the statistical model ensemble for a particular station mostly does not comprise of the whole possible set of five different models. Nevertheless, it is possible to assess changes of temperature extremes based on only those models which show a robust relationship between the large-scale predictors and the local extremes, because assessments have to be interpreted only with respect to the general tendency of changes during the 21st century, not regarding any short-term variability.

- Despite a more or less similar performance of the largescale predictors regarding the skill to reproduce the extremes indices in the observational period, the downscaling results for future projections can vary considerably depending on the particular predictors used for the statistical assessments. Especially the 95th percentile of maximum temperatures in summer in the western parts of the Mediterranean area exhibits a strong sensitivity to the choice of predictors or predictor combinations. Climatic (e.g. large-scale temperature fields) as well as dynamic factors (e.g. fields representing the atmospheric circulation) influence extreme temperature conditions and should be considered in a combined manner within downscaling models. But the inclusion of predictors can be further extended (as might be seen from the moderate levels of multiple correlation coefficients), for example, by considering humidity and wind conditions, too. Additionally, Van den Besselaar et al. (2010) have shown that the snow cover extent has an influence on temperature extremes, and they conclude that other factors have to also be taken into account like soil moisture and sea surface temperature. Furthermore, the different quality of the model predictors should be taken into consideration. If some predictors are more affected by model errors than others, the results have to be evaluated regarding this aspect.

- The statistical assessment of Mediterranean extreme minimum temperatures in winter and extreme maximum temperatures in summer by using the thickness of the $1000 \mathrm{hPa} / 500 \mathrm{hPa}$ layer and $500 \mathrm{hPa}$-geopotential heights as large-scale predictors indicates that the intraannual extreme temperature range will decrease in large parts of the Mediterranean area during the 21st century under enhanced greenhouse warming conditions. This is most pronounced for the eastern Mediterranean area. Thus, extreme minimum temperatures in winter are found to increase in the range of up to about $0.25^{\circ} \mathrm{C}$ over the Iberian Peninsula and up to $1{ }^{\circ} \mathrm{C}$ in the eastern Mediterranean area. Extreme maximum temperatures in summer show a slight negative trend over the Iberian Peninsula, increases of up to $0.25^{\circ} \mathrm{C}$ in the south-eastern Mediterranean area, and the maximum increase of about $0.5^{\circ} \mathrm{C}$ mainly in the central-northern Mediterranean area.

- The assessed increases for extreme minimum temperatures in winter show more consistency among the different statistical models compared to the changes for extreme maximum temperatures in summer.

- The present study strengthens the indication that changes in temperature extremes do not follow a simple shift of the whole temperature distribution to increased values. Further studies will include other statistical downscaling techniques (canonical correlation analysis, synoptic downscaling, and a combination of the latter with different transfer functions) in order to evaluate their usefulness for assessing climate extremes in the Mediterranean area.

- Finally, results will be compared to regional climate model simulations (dynamical downscaling) in order to estimate the range of supposed changes in the future.

Acknowledgements. The project is funded by the German Research Foundation under contract JA 831/7-1. The authors thank Elena Xoplaki, Harald Kunstmann and Andreas Heckl for providing station data in the Mediterranean area.

Edited by: P. Lionello

Reviewed by: two anonymous referees

\section{References}

Christensen, J. H., Hewitson, B., Busuioc, A., Chen, A., Gao, X., Held, I., Jones, R., Kolli, R. K., Kwon, W.-T., Laprise, R., Magana Rueda, V., Mearns, L., Menendez, C. G., Räisänen, J., Rinke, A., Sarr, A., and Whetton, P.: Regional Climate Projections, edited by: Solomon, S., Qin, D., Manning, M., Chen, Z., Marquis, M., Averyt, K. B., Tignor, M., and Miller, H. L., in: Climate Change 2007: The Physical Science Basis. Contribution of Working Group I to the Fourth Assessment Report of the Intergovernmental Panel on Climate Change, Cambridge University Press, Cambridge, United Kingdom and New York, NY, USA, 2007.

Dünkeloh, A. and Jacobeit, J.: Circulation dynamics of Mediterranean precipitation variability 1948-98, Int. J. Climatol., 23, 1843-1866, 2003.

Giorgi, F.: Climate change hot-spots, Geophy. Res. Lett., 33, L08707, doi:10.1029/2006GL025734, 2006. 
Gordon, C., Cooper, C., Senior, C. A., Banks, H. T., Gregory, J. M., Johns, T. C., Mitchell, J. F. B., and Wood, R. A.: The simulation of SST, sea ice extents and ocean heat transports in a version of the Hadley Centre coupled model without flux adjustments, Clim. Dynam., 16, 147-168, 2000.

Goubanova, K. and Li, L.: Extremes in temperature and precipitation around the Mediterranean basin in an ensemble of future climate scenario simulations, Global and Planetary Change, 57, 27-42, 2007.

Hertig, E. and Jacobeit, J.: Downscaling Future Climate Change: Temperature Scenarios for the Mediterranean area, Special Issue of Global and Planetary Change, 127-131, 2008.

Jacobeit, J.: Neuere Perspektiven des Klimawandels, edited by: Kulke, E. and Popp, H., in: Umgang mit Risiken, KatastrophenDestabilisierung- Sicherheit, Bayreuth, Berlin, 2008.

Jacobeit, J., Rathmann, J., Philipp, A., and Jones, P. D.: Central European precipitation and temperature extremes in relation to large-scale atmospheric circulation types, Met. Zeitschrift, 18, 397-410, 2009.

Jungclaus, J. H., Botzet, M., Haak, H., Keenlyside, N., Luo, J. J., Latif, M., Marotzke, J., Mikolajewicz, U., and Roeckner, E.: Ocean circulation and tropical variability in the coupled model ECHAM5/MPI-OM, J. Climate, 19, 3952-3972, 2006.

Kalnay, E., Kanamitsu, M., Kistler, R., Collins, W., Deaven, D., Gandin, L., Iredell, M., Saha, S., White, G., Woollen, J., Zhu, Y., Chelliah, M., Ebisuzaki, W., Higgins, W., Janowiak, J., Mo, K. C., Ropelewski, C., Wang, J., Leetmaa, A., Reynolds, R., Jenne, R., and Joseph, D.: The NCEP/NCAR 40-Year Reanalysis Project, Bull. Am. Meteorol. Soc., 77, 437-471, 1996.

Kistler, R., Kalnay, E., Collins, W., Saha, S., White, G., Woollen, J., Chelliah, M., Ebisuzaki, W., Kanamitsu, M., Kousky, V., van den Dool, H., Jenne, R., Fiorino, M.: The NCEP/NCAR 50-Year Reanalysis: Monthly Means CD-ROM and Documentation, Bull. Am. Meteorol. Soc., 82, 247-268, 2001.

Kjellström, E., Bärring, L., Jacob, D., Jones, R., Lenderink, G., and Schär, C.: Modelling daily temperature extremes: Recent climate and future changes over Europe, Climatic Change, 81, doi:10007/s10584-006-9220-5, 2007.

Klein Tank, A. M. G., Wijngaard, J. B., Können, G. P., Böhm, R., Demarée, G., Gocheva, A., Mileta, M., Pashiardis, S., Hejkrlik, L., Kern-Hansen, C., Heino, R., Bessemoulin, P., MüllerWestermeier, G., Tzanakou, M., Szalai, S., Pálsdóttir, T., Fitzgerard, D., Rubin, S., Capaldo, M., Maugeri, M., Leitass, A., Bukantis, A., Aberfeld, R., Van Engelen, A. F. V., Forland, E., Mietus, M., Coelho, F., Mares, C., Razuvaev, V., Nieplova, E., Cegnar, T., Antonio López, J., Dahlström, B., Moberg, A., Kirchhofer, W., Ceylan, A., Pachaliuk, O., Alexander, L. V. and Petrovic, P.: Daily dataset of the 20th-century surface air temperature and precipitation series for the European climate assessment, Int. J. Climatol., 22, 1441-1453, 2002.

Kunstmann, H., Heckl, A., and Rimmer, A.: Physically based distributed hydrological modelling of the Upper Jordan catchment and investigation of effective model equations, Adv. Geosci., 9, 123-130, doi:10.5194/adgeo-9-123-2006, 2006.

Mann, H. B. and Whithney, D. R.: On a test whether one of two random variables is stochastically larger than the other, Ann. Math. Statist., 18, 50-60, 1947.

Mann, H. B.: Nonparametric test against trend, Econometrica, 13, 245-259, 1945.
Moberg, A., Jones, P. D., Lister, D., Walther, A., Brunet, M., Jacobeit, J., Alexander, L. V., Della-Marta, P., Luterbacher, J., Yiou, P., Chen, D., Klein Tank, A., Saladié, O., Sigró, J., Aguilar, E., Alexandersson, H., Almarza, C., Auer, I., Barriendos, M., Begert, M., Bergström, H., Böhm, R., Butler, C. J., Caesar, J., Drebs, A., Founda, D., Gerstengarbe, F.-W., Micela, G., Maugeri, M., Österle, H., Pandzic, K., Petrakis, M., Srnec, L., Tolasz, R., Tuomenvirta, H., Werner, P. C., Linderholm, H., Philipp, A., Wanner, H. and Xoplaki, E.: Indices for daily temperature and precipitation extremes in Europe analysed for the period 1901-2000, J. Geophys. Res.-Atmos., 111, D22106, doi: 10.1029/2006JD007103, 2006.

Moberg, A. and Jones, P. D.: Trends in indices for extremes in daily temperature and precipitation in central and western Europe, 1901-99, Int. J. Climatol., 25, 1149-1171, 2005.

Nakicenovic, N., Swart, R. (eds): Emissions Scenarios 2000. Special Report of the Intergovernmental Panel on Climate Change, Cambridge University Press, Cambridge, 570 pp., 2000.

Philipp, A., Della-Marta, P. M., Jacobeit, J., Fereday, D. R., Jones, P. D., Moberg, A., and Wanner, W.: Long term variability of daily North Atlantic-European pressure patterns since 1850 classified by simulated annealing clustering, J. Climate, 20(16), 40654095, 2007.

Pope, V., Gallani, M. L., Rowntree, P. R., and Stratton, R. A.: The impact of new physical parameterizations in the Hadley Centre climate model: HadAM3, Clim. Dynam., 16, 123-146, 2000.

Preisendorfer, R. W.: Principal Component Analysis in Meteorology and Oceanography, Developments in Atmospheric Science 17, Amsterdam, 1988.

Rapp, J. and Schönwiese, C.-D.: Atlas der Niederschlags- und Temperaturtrends in Deutschland 1891-1990, Frankfurter Geowissenschaftliche Arbeiten, Serie B, Band 5, Frankfurt, 1995.

Roeckner, E., Brokopf, R., Esch, M., Giorgetta, M., Hagemann, S., Kornblueh, L., Manzini, E., Schlese, U., and Schulzweida, U.: Sensitivity of simulated climate to horizontal and vertical resolution in the ECHAM5 atmosphere model, J. Climate, 19, 3771-3791, 2006a.

Roeckner, E., Brasseur, G. P., Giorgetta, M., Jacob, D., Jungclaus, J., Reick, C., and Sillmann, J.: Climate projections for the 21st century, Max Planck Institute for Meteorology, Hamburg, 2006b.

Tebaldi, C., Hayhoe, K., Arblaster, J. M., and Meehl, G. A.: Going to the extremes. An intercomparison of model-simulated historical and future changes in extreme events, Clim. Change, 79, 185-211, 2006.

Tomozeiu, R., Cacciamani, C., Pavan, V., Morgillo, A., and Busuioc, A.: Climate change scenarios for surface temperature in Emilia-Romagna (Italy) obtained using statistical downscaling models, Theoretical and Applied Climatology, 90, 25-47, 2007.

Van den Besselaar, E. J. M., Klein Tank, A. M. G., and van der Schrier, G.: Influence of circulation types on temperature extremes in Europe, Theoretical and Applied Climatology, 99, 431-439, 2010.

Von Storch, H. and Zwiers, F. W.: Statistical Analysis in Climate Research, Cambridge University Press, Cambridge, 484 pp., 1999.

Wijngaard, J. B., Klein Tank, A. M. G., and Können, G. P.: Homogeneity of 20th century European daily temperature and precipitation series, Int. J. Climatol., 23, 679-692, 2003. 